\title{
The Application of Multimedia CAI Teaching in Football Course of Higher Vocational Colleges
}

\author{
Xiaofeng Long \\ (Wuhan Institute Of Shipbuilding Technology, Hubei Wuhan, 430050, \\ 1ongxiaofeng@hotmail.com)
}

\section{Keywords: Higher vocational colleges; Football course; Teaching quality; Multimedia CAI}

\begin{abstract}
As football is crucial part in physical education of higher vocational colleges as well as one of sports events that are well received by students in physical teaching in higher vocational colleges, its teaching methods will directly affect quality of teaching. In current physical education system and related teaching links, it exists numerous problems in football course in China's higher vocational colleges, which constraint students' interests to certain degree and negatively impact teaching quality. Starting from actual situation, this paper will analyze related problems generated in football teaching process and put forward introducing multimedia CAT teaching design in football course.
\end{abstract}

\section{Characteristics of Football}

Rule of football sport. Football sport is to organically combine various factors such as space and time and shoot ball into the goal of counterparts through mutual delivery between players. Its strategic lineups and technological means own three unique rules of modern sports: coordination, team orientation and instantaneity. Firstly, as students shoot ball in goal through somatic function, they need to possess certain capacities to control and coordinate physical bodies; Secondly, during competition process, it requires players to cooperate in skills and tactics; Thirdly, it become keys in football sport to strengthen students' sense of time, improve accuracy and reduce error rate, in accordance with time limitation with difference characteristics in competitions.

The content diversity of football sport. Football is considered as a subject belonging to scientific competition as well sideline of the science. The diversity and comprehensiveness in content structure of football course make it become a unique sport system, including specialized theoretical basis, ego sport consciousness, body shape, stamina condition, skilled movement, tactics coordination, fatigue recovery, trauma precaution and treatment supervision and make these factors mutual penetration into a integral whole. As a result, football sport itself is relative rich in content structure and owns characteristics of pluralism, scientificity and peculiarity.

Comprehensiveness in football teaching. Football is a comprehensive competitive sport. Compared with other sports, football is more complicated. With various skilled movements and tactics forms, it need to contend centering on spacial short-term fluctuation as well as combine individual actions and team cooperation, space and ground, time and speed, confrontation and strategies. Different from other physical exercises, football put more emphasis on its own instantaneity and comprehensiveness.

\section{Problems Existed in Football Teaching of Higher Vocational Colleges}

On $27^{\text {th }}$, February, 2015, Mr. Xinjinping, the General Secretary of the Communist Party of China, state president, chairman of Central Military Commission and group leader of the leading group for comprehensive deepening reform hosted the tenth meeting of deepening reform and deliberated and approved The General Plan for China Football Reform, which was the meeting with top specification in national level. The participation of Mr.Xi in this meeting injected the most powerful executive force in China's football reform.

Lack of innovation in teaching content and pattern. With strengthened national attention on football and reforms of educational concept of campus football, it should also make corresponding 
adjustment and changes in teaching ideas of football concept of higher vocational colleges. However, as researches suggested, teaching concepts fall behind for many football gym instructors in higher vocational colleges, especially for elder ones. They fail to accurately grasp the actual demands of modern football teaching and unconsciously constraint students' improvement and personality development in teaching process so that they can not offer the platform suitable for their own subjective development and affect overall teaching quality to certain extent.

In addition, their teaching contents are merely limited to basic football movement teaching and merely lay emphasis on practice of students' football, but they can not acquire standardization and mastery of essences of football skilled movements and lack of training and guidance on students' football theoretical course. This phenomenon directly result in students' disorder behaviors in football operational process and their poor comprehensions on football rules and theories. In addition, many gym teachers can not satisfy students' individual sport demands and usually use fixed teaching schedule, resulting in their poor football foundation. Students majoring in football can not adapt to football teaching and practice, making it difficult to carry out teaching ideas.

Prominent phenomenon that conduct practice without theories in teaching process. The survey indicated that in current football teaching process of higher vocational colleges, all the teaching contents are completed in the football field. Football teaching lay entire emphasis on practice and nearly all teachers never carry out related teaching course of football knowledge theories, giving rise to the front heaviness problem in football teaching of higher vocational colleges. The gym teachers over-emphasize practice, but neglect theory teaching, which is prone to students' lack of recognition on football rules and other knowledge, let alone specialized football skills and team coordination. With strong randomness in daily teaching process, it is difficult to motivate students' learning initiative. The discordance of practice training and teaching theories directly affect actual teaching and training effects.

Incomplete evaluation system of football course. Evaluation process on football course and its competitiveness in higher vocational colleges can reflect students' grasp degree on football skills and physical quality indeed, but this objective evaluation standard ignore assessment system and method on students' mastery on football professional knowledge,skills and tactics. Therefore, evaluation method is too simple and can not reflect students' comprehensive qualities and tactical application ability.

Teaching facilities can not satisfy teaching demands. Football teaching facilities will directly affect its teaching quality. Many problems exists in current numerous higher vocational colleges such as nonstandard football field, old-fashioned teaching facilities and backward teaching equipment. As investigations on football facilities of higher vocational colleges suggested, most football fields are hard to meet teaching demands. Meanwhile, no specialized staffs are in charge of football facilities, foreign personnel are complicated and mixture phenomenon of teaching staffs and non-teaching staff are specially severe, which directly affect their football teaching quality. With continuous expansion of students majoring in football in China's higher vocational colleges, supporting facilities are severely insufficient and worn-out equipment can not be replaced in a timely manner, resulting in severe security hazards. In particular, football field never expand and related departments neglect management on the field so that it cause severe source confrontation and can not satisfy normal football teaching demands.

\section{Significance of Multimedia CAI on Football Teaching}

Courseware of Multimedia CAI (computer aided instruction) is a kind of courseware that through confirmation of teaching objectives, contents, task analysis, teaching activity structure and interfacial design, computer process and control multimedia and carry out hyper-text structure production. It can be used for storage, delivery and disposal of teaching information, make students be able to carry out interactive operations and evaluate students' study. CAI owns diversity of the teaching information carrier, digital trait of teaching information processing, hyper text characteristic of teaching information organization, interaction of teaching information manifestation and diagnosability of teaching process. It can optimize class teaching structure, 
benefit to highlight teaching keys, break through nodus and cultivate students' multidimensional thinking mode. Therefore, CAI can effectively improve teaching efficiency and create multi-layer study goal for students.

Improve and strengthen recognition memory. Sense organs of human beings can firstly understand objective things, acquire related information through auditory sense and vision, transmit processed information to nerve cell in cerebral cortex and gradually form thoughts and memories through judgement and analysis. The youth perceive is based on iconic memory and thoughts and transferred into organism memory capacity under coordination of various receptors. CAI technique take perceive procedure of human brain and material transfer process as characteristics, process corresponding information through computer, stimulate students' sense organ by the means of photo display, word, voice, video and other forms and improve students' interests on football study and objective recognition on football tactics to improve effects of football course and teaching.

Strengthen effects of theoretical teachings. Vivid multimedia CAI technique can stimulate students' learning enthusiasm on football and improve teaching effects. During teaching process of related football theories and movement standardization, traditional blackboard teaching and rigid movement demonstration strike students' enthusiasm on studying football. Especially when studying various decomposition of football movement, teachers can only display related wall maps and static demonstrations to students and are unable to make students continually seize dynamic overall process of football sport. However, CAI can faithfully reflect relationship between movements through dynamic images and make use of slow motion and close-up method to display more vividly. As teachers interpret football theories and rules, they can choose to correctly insert into a series characters and animation photos, which can make students seize related knowledge more intuitively in the shortest time. In addition, multimedia also owns interaction function, so it can mobilize students' interests on self-learning and actively participate in it, gradually transferring from passive learning to active learning. We cam utilize multimedia technique to improve learning environment, cultivate students' learning quality and improve learning achievement.

Emphasize related learning goal. CAI football teaching courseware can make it available for teachers to guide students to strengthen their weak links in the football practices and continually emphasize students to improve their own performance on football. Students can choose and confirm their own study direction in line with CAI courseware, formulate studying goals and strengthen targeted practices to complete stated objectives of their courses.

Improve students' analysis ability. In traditional football teaching process, students are unfamiliar with related football rules. Consequently, gym instructors lay more emphasis on analysis of teaching cases. Teachers merely explained related cases and students is unable to genuinely understand it only by listening. If it goes on like this, it will deviate from teaching goals. However, CAI can combine characters and videos and other methods, intuitively display teaching content to students and deepen students' impression through teachers' orientation explanations.

\section{Application of CAI Teaching in the Foot Courses of Higher Vocational Colleges}

CAI teaching method reflects teaching content, process and strategies mainly through text, static photos, animation, audio and videos and other elements. It owns functions such as human-computer interaction interface, diagnosis and evaluation and feedback and intensity. It demonstrates unparalleled superiority compared with traditional education and change traditional teaching method. The vivid and illustrated CAI tool solve numerous shortcomings of traditional teachings in the assisted teaching process. The application in teaching with its powerful functions will stimulate rapid development of education modernization.

Make scientific choices on football course. The selection principle of football teaching should make scientific and practical choices and designs in line with characteristics of football programs and objective rules of students' individual growth. It can should put diversity of football sport in priority. As a complicated systematic project, it should take scientific and comprehensive considerations from students' physiological and mental conditions and other section. Secondly, it 
need to abide by dynamics rule. As students are in the dynamic process of growth, football movement techniques and requirements should change accordingly. This dynamics nature is firstly reflected on indicator dimensionality and then assessment latitude. With constant development of football exercises and technical skills as well science and technology, different evaluation indicators should make adjustment and improvement in a timely manner in line with students' specific qualities. By data reduction and technological means, these indicator data can be displayed more vividly to students through multimedia CAI teaching method.

Expand teaching forms and change teaching methods. The current football courses in higher vocational colleges are still dominated by traditional teaching mode. Although it can build teachers' absolute predominance on teaching process, it still lake of certain interaction to make students actively participate football course and tactics training. During implementation process, it is through vast repeated exercises and proficiency on fixed knowledge points that traditional teaching mode make students unconsciously master basic football movements. As a result, it will result in baldness in the students' learning process. If incorporated multimedia CAI, positive effects will be generated no matter from students' exercise physiology or psychology. By diversified attempts and guidance, CAI teaching method can make students fully utilize their own sense organs to understand and try football techniques, stimulate their studying enthusiasm, create active class atmosphere and cultivate their lifelong sport consciousness and collective spirit. Taking mutual and organic integration of students' football tactics and ideas in current stage as the goal and make it run thorough the entire football teaching process. Guide students to make proper adjustments in line with football course outline of each semester and teaching objectives, principles, principles, technical training and tactical instructions.

Proper application of multimedia CAI. The proper introduction of CAI teaching method in football course can easily stimulate students' interests and interactions. In the process of interpreting football rules and tactic changes in particular, utilize multimedia teaching methods to pause, reply in slow motion and repeat play related video documents, combine characters and photos and form teaching content integrating static state and dynamic condition so that it can mobilize students' studying interests and enthusiasm on learning. For example, during teaching of football techniques and tactics, students can more visually understand coordination of tactic changes by watching videos. Utilize play in low speed or repeated play to make students distinctly see athletes' cooperation forms, play movement, opportunities of pass and catch and applications of technical movements, changing their studying type from passive method towards active one.

Improve assessment and evaluation content and system. Traditional football assessment method in China's higher vocational colleges tends to emphasize students' competitive links such as running, jumping shooting. It is merely through simple competitive means and measurement data such as time, height and accuracy that reflect students' studying and mastery on football course, but neglect their individual differences, which will negatively affect students' basic sport capacity and improvement of overall qualities. As one of important decision makings of football teaching reform in higher vocational colleges, reforms of football teaching contents and methods put forward new requirements on curriculum evaluation and assessment plans. On the basis of students' specific situations, pay attention on evaluations on final data as well assessments on teaching course in the entire teaching assessment process. Comprehensively carry out assessment from students' mastery on basic football technical capacity, synthetic ability, self-study ability and attendance rate and choose quantitative assessment indicators. Correctly make use of evaluation and assessment method of "teaching integrity" to benefit to teaching integration.

\section{Conclusion}

To sum up, CAI technique is to assist traditional teaching modes, fully utilize computer characteristics and unfold vivid static and dynamic images and photos before students' eyes. Consequently, it can mobilize students' interests on football theory knowledge, motivate them actively participate in teaching activities and cultivate students' overall qualities. CAI courseware breaks up traditional teaching mode of passive acceptance. Meanwhile, by virtue of interaction 
function of multimedia, it plays students' leading role, largely shorten studying time, improve teaching effects and quality and perfect the overall teaching goal.

\section{Reference}

[1] Several teaching methods and notices of in football teaching [J]. Jeky. Modern enterprise education.2009 (12)

[2] Experimental research on the application of multimedia technology and imagery training in football technology teaching class $[\mathrm{J}]$. Zhang $\mathrm{Wu}$, Ke Chang long, Journal of Hubei Normal University (NATURAL SCIENCE EDITION).2008 (03)

[3] The advantages of introducing multimedia technology to traditional science teaching mode in science experiment class [J]. Yang Lijing. Communication world.2017 (02)

[4] University soccer fans sports injury prevention and measures [J]. Cheng Jie. Contemporary sports science and technology.2016 (35)

[5] Soccer enthusiasts' participation in motivation, sports value and happiness: [J]. Xiang Xin. Sports fashion.2018 (03)

[6] Physical education in Colleges and Universities -- Discussion on football teaching reform [J]. Yan Xian Liang. Examination week.2007 (42)

[7] Research on the auxiliary function of multimedia technology in physical education teaching [J]. Wang Lei. Wireless Interconnect Technology.2017 (08)

[8] Summary of the development trend of football teaching in Chinese colleges and universities [J]. Zhang Chun, Jing Qiao, Xu Jingchao. Hebei enterprise.2015 (11)

[9] Cui Yongmei. Application of modern information technology in college football teaching. Education in [J]. era, 2016 (7): 211.

[10] Thoughts on the construction of China's soccer video resources library [J]. Chen Cai Ying. Sports world (Academic Edition).2015 (10)

[11] Thoughts on the construction of teaching and research PE teachers in Chinese universities and colleges [J]. Lin Xiao Ping. Education and occupation.2015 (27)

[12] Talking about the grouping mode of computer education and teaching [J]. Zhang Hui Hui. Software.2014 (01)

[13] On the reorientation of the teaching content of football course in Colleges and universities [J]. Wei Bin, Ouyang Zhao. Contemporary sports science and technology.2013 (30) 